\title{
The Preschool-Aged and School-Aged Children Present Different Odds of Mortality than Adults in Southern Taiwan: A Cross-Sectional Retrospective Analysis
}

\author{
Shu-Hui Peng ${ }^{1}$, Chun-Ying Huang ${ }^{2}$, Shiun-Yuan Hsu ${ }^{2}$, Li-Hui Yang ${ }^{3,4, *, \dagger}$ \\ and Ching-Hua Hsieh 1,*, + (iD) \\ 1 Department of Plastic Surgery, Kaohsiung Chang Gung Memorial Hospital, Chang Gung University College \\ of Medicine, Kaohsiung 83301, Taiwan; pshui@cgmh.org.tw \\ 2 Department of Trauma Surgery, Kaohsiung Chang Gung Memorial Hospital, Chang Gung University \\ College of Medicine, Kaohsiung 83301, Taiwan; junyinhaung@yahoo.com.tw (C.-Y.H.); \\ ah.lucy@hotmail.com (S.-Y.H.) \\ 3 Department of Nursing, Kaohsiung Chang Gung Memorial Hospital, Chang Gung University College of \\ Medicine, Kaohsiung 83301, Taiwan \\ 4 Department of Nursing, Meiho University, Pingtung County 91202, Taiwan \\ * Correspondence: amy1123@cgmh.org.tw (L.-H.Y.); m93chinghua@gmail.com (C.-H.H.); \\ Tel.: +886-7-7317123 (L.-H.Y.) (ext. 2041); +886-7-3454746 (C.-H.H.) \\ + These authors contribute equally to this paper.
}

Received: 26 March 2018; Accepted: 21 April 2018; Published: 25 April 2018

Abstract: Background: This study aimed to profile the epidemiology of injury among preschool-aged and school-aged children in comparison to those in adults. Methods: According to the Trauma Registry System of a level I trauma center, the medical data were retrieved from 938 preschool-aged children (aged less than seven years), 670 school-aged children (aged 7-12 years), and 16,800 adults (aged 20-64 years) between 1 January 2009 and 31 December 2016. Two-sided Pearson's, chi-squared, and Fisher's exact tests were used to compare categorical data. A one-way analysis of variance (ANOVA) with the Games-Howell post-hoc test was used to assess the differences in continuous variables among different groups of patients. The mortality outcomes of different subgroups were assessed by a multivariable regression model under the adjustment of sex, injury mechanisms, and injury severity. Results: InFsupppjury mechanisms in preschool-aged and school-aged children were remarkably different from that in adults; in preschool-aged children, burns were the most common cause of injury requiring hospitalization (37.4\%), followed by falls (35.1\%) and being struck by /against objects $(11.6 \%)$. In school-aged children, injuries were most commonly sustained from falls $(47.8 \%)$, followed by bicycle accidents $(14 \%)$ and being struck by /against objects $(12.5 \%)$. Compared to adults, there was no significant difference of the adjusted mortality of the preschool-aged children $(\mathrm{AOR}=0.9 ; 95 \% \mathrm{CI} 0.38-2.12 ; p=0.792)$ but there were lower adjusted odds of mortality of the school-aged children (AOR $=0.4 ; 95 \%$ CI $0.10-0.85 ; p=0.039$ ). The school-aged children had lower odds of mortality than adults (OR, $0.2 ; 95 \%$ CI, $0.06-0.74 ; p=0.012)$, but such lower odds of risk of mortality were not found in preschool-aged children (OR, 0.7; 95\% CI, 0.29-1.81; $p=0.646)$. Conclusions: This study suggests that specific types of injuries from different injury mechanisms are predominant among preschool-aged and school-aged children. The school-aged children had lower odds of mortality than adults; nonetheless there was no difference in mortality rates of preschool-aged children than adults, with or without controlling for sex, injury mechanisms and ISS. These results highlight the importance of injury prevention, particularly for preschool-aged children in Southern Taiwan. 
Keywords: preschool-aged children; school-aged children; injury; pediatric trauma; mortality; trauma registry

\section{Introduction}

This study showed that one in four children in the United States will sustain an unintentional injury requiring emergency treatment [1,2], leading to over 8.7 million hospital visits each year $[3,4]$. In addition, trauma is the leading cause of mortality and acquired disability in children [5-7], causing 12,000 injury-related deaths [8] and accounting for 34\% of all child mortality annually in the United States [9]. However, compared to adults, children had lower reported trauma-related mortality rates in the United States: The fatalities were 12.69, 3.69 and 3.7 per 100,000 persons in pediatric population aged $0-4$ years, $5-9$ years and 10-14 years respectively; compared to 45.30 fatalities per 100,000 persons in adults aged 20-64 years [9].

Compared with adults, children present different patterns of injury [10]. The pattern and circumstances of injuries change as children progress with age [11]. Obviously, the etiology of injuries is complex; it differs from children to adults and even from country to country. Furthermore, the physiological responses $[12,13]$ and capacity to thrive [14] might be different in children and adults. Therefore, to reduce the injury to children, it is important to understand the associated injury patterns and outcomes for children [15]. However, in Taiwan, most of previous studies on children injury focus on trauma due to specific etiology such as child abuse [16,17], burns [18] or head injuries [16,19]. Therefore, to explore the epidemiological profile of child injury under the hypothesis that the children would have a lower mortality rate than adults in Taiwan, the first objective of this study was to systematically examine the rates of child injury among preschool-aged and school-aged children compared to those of adults. The secondary objective was to investigate whether preschool-aged and school-aged children had a better expected mortality outcome than adults, in the absence or presence of adjusting potential confounders including sex, injury mechanism, and injury severity. This article focused on trauma of children and did not include the teenagers, who are at high risk for experiencing traumatic events and respond differently to injury [20]. In this goal, the mortality rate would be measured as the primary outcome.

\section{Methods}

\subsection{Ethical Statement}

The retrospective study was performed after receiving approval from the institutional review board (IRB) of Chang Gung Memorial Hospital (approval number: 201701671B0). Informed consent requirements were waived according to the regulations of IRB. All analyses were conducted using de-identified secondary data, with no means to link the information to individual respondents.

\subsection{Study Design}

In this study, patients were stratified as preschool-aged children (aged less than 7 years), school-aged children (aged 7-12 years), and adults (aged 20-64 years). Out of the 27,462 hospitalized patients enrolled in the Trauma Registry System from 1 January 2009 to 31 December 2016 for all-causes of trauma, 938 were preschool-aged children, 670 were school-aged children, and 16,800 were adults; the 325 adult patients who had incomplete registered data were excluded (Figure 1). We retrieved the detailed patient information from the registry database, including age, trauma mechanism, helmet use, initial Glasgow Coma Scale (GCS) score upon arrival at the emergency department, Injury Severity Score (ISS), Abbreviated Injury Scale (AIS) score in each body region, rates of sustained injuries in each body region, and in-hospital mortality [21,22]. The AIS is an anatomically based measurement of injury severity to rank specific injuries as minor (1), moderate (2), serious (3), severe (4), critical 
(5), and unsurvivable (6). The ISS was created based on the AIS severity values using the sum of the squares of the severity digit in the AIS of most severe injuries in three of six body regions [23].

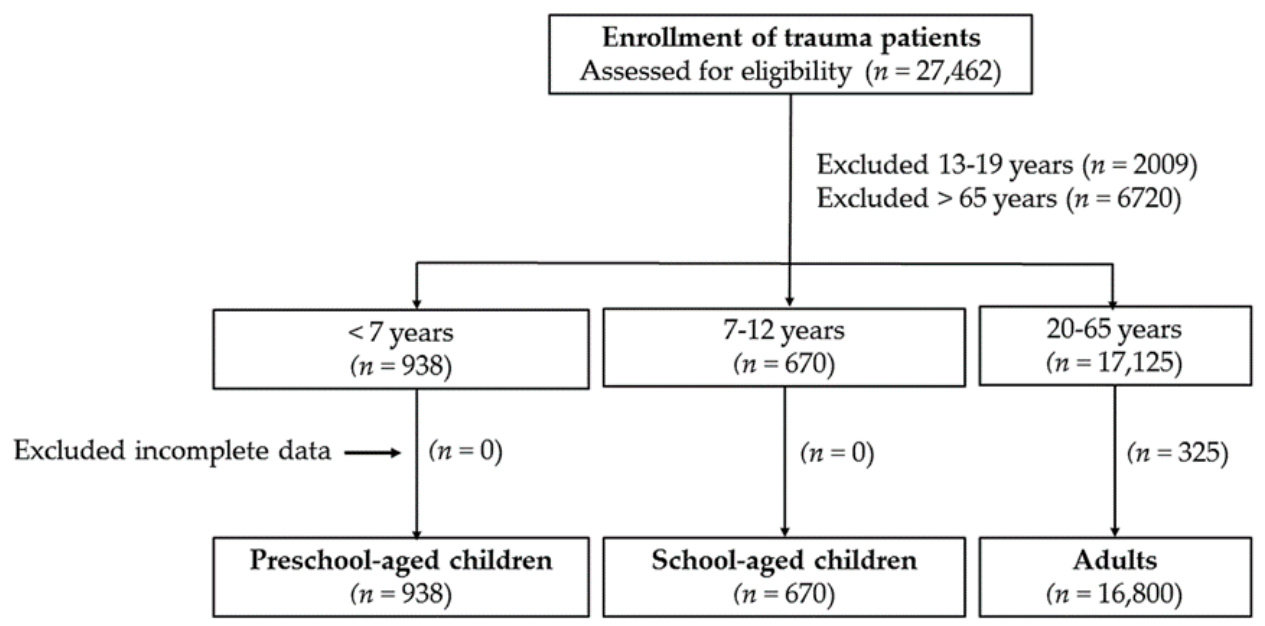

Figure 1. Flow chart of the distribution of the studied population into preschool-aged children, school-aged children, and adults.

\subsection{Statistical Analysis}

The ISS is expressed as the median and interquartile range (IQR, Q1-Q3). The obtained data were compared using the IBM SPSS Statistics for Windows version 22.0 (IBM Corp., Armonk, NY, USA). Categorical data were compared using either a chi-squared test or a two-sided Fisher's exact test. The odds ratios (ORs) of the associated conditions and bone fractures of the patients were calculated with $95 \%$ confidence intervals (CIs). The homogeneity of variance of the continuous data was initially estimated using Levene's test, then a one-way analysis of variance (ANOVA) with the Games-Howell post-hoc test was used to assess the differences of continuous variables among different groups of patients. The continuous data were expressed as mean \pm standard deviation. The difference in ISS distribution among different subgroups of patients was analyzed using Kruskal-Wallis nonparametric test. The ISS was expressed as the median and interquartile range (IQR, Q1-Q3). The adjusted odds ratios (AORs) and 95\% CIs for mortality were calculated by using a multivariable regression model adjusted for sex, trauma mechanisms, and ISS. The mortality outcomes were assessed by a binary logistic regression. The mortality outcomes in different subgroups were assessed with a multivariable regression model adjusted for sex, injury mechanisms, and injury severity. $p$-values $<0.05$ were considered statistically significant.

\section{Results}

\subsection{Injury Characteristics and Severity of the Patients}

As shown in Table 1, there was no significant difference in sex predominance between preschool-aged, school-aged children and adults. The injury mechanisms in preschool-aged and school-aged children were different from those in adults; in preschool-aged children, burns were the most common cause of injury requiring hospitalization (37.4\%), followed by falls $(35.1 \%)$ and being struck by/against an object (11.6\%). In school-aged children, injuries were most commonly sustained from falls, followed by bicycle accidents (14\%) and being struck by/against an object $(12.5 \%)$. Motorcycle accidents occurred more frequently in adults and comprised around half of the admitted patients. Injuries such as injuries from motorcycle pillion accidents, injuries due to falls, and burn injuries were significantly higher in both preschool-aged and school-aged children than adult patients. The helmet use was significantly associated with a lower odds of head injury, defined by head AIS $\geq 2$, 
in school-aged children (OR 0.1; 95\% CI 0.02-0.37; $p<0.001$ ) but not in preschool-aged children (OR 0.7; 95\% CI 0.21-2.31; $p=0.768$ ) (Supplementary Materials Table S1). The percentage of preschool-aged children, but no school-aged children, sustaining pedestrian and bite-related injuries is higher than that of adults (Table 1).

Most of the patients had a GCS score of $\geq 13$ and fewer had a GCS score of $\leq 8$. The GCS scores in preschool-aged and school-aged children were significantly lower than those of adults, notwithstanding that the GCS score difference between these groups was less than one point (Table 2). The AIS analysis revealed that preschool-aged and school-aged children had lower rates of injuries in each body region than adults; however, preschool-aged children had higher rates of external injuries, predominantly burns, than adults. Moreover, preschool-aged and school-aged children had a significantly lower ISS compared with adults (Table 2). When stratified using ISS ( $<16,16-24$ or $\geq 25)$, fewer preschool-aged and school-aged children had an ISS of $\geq 25$ and 16-24, respectively, and more had an ISS of $<16$ than adults (Table 1 ).

As regards associated injuries, preschool-aged and school-aged children had lower odds of different injuries in the six main body regions (Supplementary Materials Tables S2 and S3). On the other hand, there was a 4.4 -fold $(95 \%$ CI, 3.70-5.25; $p<0.001)$ and 4.1 -fold $(95 \%$ CI, 3.35-5.07; $p<0.001)$ increase in the odds of humeral fracture among preschool-aged and school-aged children respectively (Table 3). Compared with adults, preschool-aged children had a lower odds of radial fracture (OR, $0.4 ; 95 \% \mathrm{CI}, 0.30-0.55 ; p<0.001)$ and ulnar fracture (OR, $0.7 ; 95 \% \mathrm{CI}, 0.47-0.96 ; p=0.032)$, whereas school-aged children had a higher odds of radial fracture (OR, 3.2; 95\% CI, 2.68-3.81; $p<0.001)$ and ulnar fracture (OR, 3.2; 95\% CI, 2.59-4.05; $p<0.001)$.

\subsection{Patient Outcomes and Associated Injuries}

As shown in Table 4, the mortality rates between preschool-aged children and adults were not significantly different. By contrast, the mortality odds ratio in school-aged children was lower than that in adults (OR, 0.3; 95\% CI, 0.09-0.92; $p=0.031)$. Further, compared to adults, there was no significant difference in the adjusted mortality of the preschool-aged children (AOR $=0.9 ; 95 \%$ CI 0.38-2.12; $p=0.792)$ but lower adjusted odds of mortality of the school-aged children (AOR $=0.4$; $95 \%$ CI $0.10-0.85 ; p=0.039$ ). Notably, in this study, although there was a higher occurrence of burn injuries in preschool-aged children $(37.4 \%, n=351)$ than school-aged children $(11.3 \%, n=76)$ and adults $(3.4 \%, n=570)$, the mortality of preschool-aged children $(0.6 \%, n=2)$ with a burn was significantly lower $(\mathrm{OR}=0.3 ; 95 \% \mathrm{CI} 0.05-1.01 ; p=0.037)$ than that of adults $(2.5 \%, n=14)$ and the mortality rates of school-aged children $(3.9 \%, n=3)$ and adults were not significantly different $(\mathrm{OR}=1.6 ; 95 \%$ CI $0.46-5.82 ; p=0.708$ ). Therefore, the unexpectedly high mortality rates of preschool-aged children cannot be explained by the higher proportion of burn injuries in preschool-aged patients. 
Table 1. Injury characteristics of categorical variables in preschool-aged children, school-aged children, and adults.

\begin{tabular}{|c|c|c|c|c|c|c|c|c|}
\hline $\begin{array}{l}\text { Variables } \\
\text { Sex, n (\%) }\end{array}$ & \multicolumn{2}{|c|}{ Preschool-Aged Child $n=938$} & \multicolumn{2}{|c|}{ School-Aged Child $n=670$} & \multicolumn{2}{|c|}{ Adult $n=16,800$} & $\begin{array}{c}\boldsymbol{P} \\
\text { Preschool-Aged Child vs. Adult } \\
0.084\end{array}$ & $\begin{array}{c}\boldsymbol{P} \\
\text { Preschool-Aged Child vs. Adul } \\
0.351\end{array}$ \\
\hline Male & 554 & $(59.1)$ & 427 & $(63.7)$ & 10,399 & (61.9) & & \\
\hline Female & 384 & $(40.9)$ & 243 & $(36.3)$ & 6401 & $(38.1)$ & & \\
\hline \multicolumn{9}{|l|}{ Mechanisms, n (\%) } \\
\hline Driver (motor vehicle) & 0 & $(0.0)$ & 0 & $(0.0)$ & 328 & $(2.0)$ & $<0.001$ & $<0.001$ \\
\hline Passenger (motor vehicle) & 7 & $(0.7)$ & 8 & $(1.2)$ & 166 & $(1.0)$ & 0.505 & 0.690 \\
\hline Driver (motorcycle) & 0 & $(0.0)$ & 3 & $(0.4)$ & 8012 & $(47.7)$ & $<0.001$ & $<0.001$ \\
\hline Pillion (motorcycle) & 63 & $(6.7)$ & 64 & $(9.6)$ & 358 & $(2.1)$ & $<0.001$ & $<0.001$ \\
\hline Bicyclist & 28 & (3.0) & 94 & $(14.0)$ & 435 & $(2.6)$ & 0.460 & $<0.001$ \\
\hline Pedestrian & 36 & (3.8) & 16 & $(2.4)$ & 252 & $(1.5)$ & $<0.001$ & 0.076 \\
\hline Fall & 329 & $(35.1)$ & 320 & $(47.8)$ & 3388 & $(20.2)$ & $<0.001$ & $<0.001$ \\
\hline Struck by/against & 109 & (11.6) & 84 & $(12.5)$ & 3202 & $(19.1)$ & $<0.001$ & $<0.001$ \\
\hline Bite & 15 & $(1.6)$ & 5 & $(0.7)$ & 89 & $(0.5)$ & $<0.001$ & 0.588 \\
\hline Burn & 351 & $(37.4)$ & 76 & (11.3) & 570 & $(3.4)$ & $<0.001$ & $<0.001$ \\
\hline \multicolumn{9}{|l|}{ GCS, n (\%) } \\
\hline$\leq 8$ & 19 & $(2.0)$ & 10 & $(1.5)$ & 722 & $(4.3)$ & 0.001 & $<0.001$ \\
\hline $9-12$ & 12 & (1.3) & 12 & $(1.8)$ & 523 & (3.1) & 0.002 & 0.051 \\
\hline$\geq 13$ & 907 & (96.7) & 648 & $(96.7)$ & 15,555 & $(92.6)$ & $<0.001$ & $<0.001$ \\
\hline \multicolumn{9}{|l|}{ AIS n (\%) } \\
\hline Head/Neck & 156 & $(16.6)$ & 95 & $(14.2)$ & 3870 & $(23.0)$ & $<0.001$ & $<0.001$ \\
\hline Face & 76 & $(8.1)$ & 69 & $(10.3)$ & 2926 & $(17.4)$ & $<0.001$ & $<0.001$ \\
\hline Thorax & 12 & (1.3) & 8 & $(1.2)$ & 2160 & $(12.9)$ & $<0.001$ & $<0.001$ \\
\hline Abdomen & 30 & (3.2) & 26 & (3.9) & 1104 & (6.6) & $<0.001$ & 0.006 \\
\hline Extremity & 390 & $(41.6)$ & 453 & $(67.6)$ & 12,043 & (71.7) & $<0.001$ & 0.023 \\
\hline External & 387 & (41.3) & 97 & (14.5) & 2454 & (14.6) & $<0.001$ & 0.956 \\
\hline \multicolumn{9}{|l|}{ ISS } \\
\hline$<16$ & 875 & $(93.3)$ & 623 & $(93.0)$ & 14,440 & $(86.0)$ & $<0.001$ & $<0.001$ \\
\hline $16-24$ & 46 & $(4.9)$ & 40 & $(6.0)$ & 1598 & (9.5) & $<0.001$ & 0.002 \\
\hline$\geq 25$ & 17 & (1.8) & 7 & $(1.0)$ & 762 & (4.5) & $<0.001$ & $<0.001$ \\
\hline
\end{tabular}

AIS = Abbreviated Injury Scale; CI = Confidence Interval; GCS = Glasgow Coma Scale; ISS = injury severity score; IQR = Interquartile Range. 
Table 2. Injury characteristics and outcomes of continuous variables in preschool-aged children, school-aged children, and adults.

\begin{tabular}{|c|c|c|c|c|c|c|c|c|}
\hline \multirow[b]{2}{*}{ GCS } & \multirow{2}{*}{$\begin{array}{c}\text { Preschool-Aged Child } n=938 \\
14.73 \pm 1.46\end{array}$} & \multirow{2}{*}{$\begin{array}{c}\text { School-Aged Child } n=\mathbf{6 7 0} \\
14.76 \pm 1.29\end{array}$} & \multirow{2}{*}{$\begin{array}{c}\text { Adult } \boldsymbol{n}=\mathbf{1 6 , 8 0 0} \\
14.40 \pm 2.10\end{array}$} & \multirow{2}{*}{$\begin{array}{c}\underset{A N O V A}{P} \\
<0.001\end{array}$} & \multicolumn{2}{|c|}{ Comparison between } & \multirow{2}{*}{$\begin{array}{c}\text { Mean Difference } \\
-0.03 \\
0.33 \\
0.36\end{array}$} & \multirow{2}{*}{$\begin{array}{c}\text { Post-hoc } P \\
0.925 \\
<0.001 \\
<0.001\end{array}$} \\
\hline & & & & & $\begin{array}{c}\text { Preschool-aged child } \\
\text { School-aged child }\end{array}$ & $\begin{array}{l}\text { School-aged child } \\
\text { adult } \\
\text { Adult }\end{array}$ & & \\
\hline & Preschool-Aged Child $n=938$ & school-Aged Child $n=670$ & Adult $n=16,800$ & $\begin{array}{c}\text { Kruskal-Wallis } \\
P\end{array}$ & & & Median Difference & Post-hoc $P$ \\
\hline ISS & $4(1-4)$ & $4(4-9)$ & $5(4-9)$ & $<0.001$ & $\begin{array}{l}\text { Preschool-aged child } \\
\text { School-aged child }\end{array}$ & $\begin{array}{l}\text { School-aged child } \\
\text { Adult } \\
\text { Adult }\end{array}$ & $\begin{array}{c}0 \\
-1 \\
-1\end{array}$ & $\begin{array}{l}<0.001 \\
<0.001 \\
<0.001\end{array}$ \\
\hline
\end{tabular}

GCS = Glasgow coma scale; ISS = injury severity score .

Table 3. Associated injuries with higher odds of incidence among preschool-aged and school-aged children than in adults.

\begin{tabular}{|c|c|c|c|c|c|c|c|c|c|c|c|c|}
\hline \multirow[t]{2}{*}{ Variables } & \multicolumn{2}{|c|}{ Preschool-Aged Child } & \multicolumn{2}{|c|}{ School-Aged Child } & \multicolumn{2}{|c|}{ Adult } & \multicolumn{2}{|c|}{ OR $(95 \% \mathrm{CI})$} & $P$ & \multicolumn{2}{|c|}{ OR $(95 \%$ CI $)$} & $P$ \\
\hline & \multicolumn{2}{|c|}{$n=938$} & \multicolumn{2}{|c|}{$n=670$} & \multicolumn{2}{|c|}{$n=16,800$} & \multicolumn{3}{|c|}{ Preschool-Aged Child vs. Adult } & \multicolumn{3}{|c|}{ School-Aged Child vs. Adult } \\
\hline Humeral fracture & 182 & $(19.4)$ & 123 & $(18.4)$ & 870 & $(5.2)$ & 4.4 & $(3.70-5.25)$ & $<0.001$ & 4.1 & $(3.35-5.07)$ & $<0.001$ \\
\hline Radial fracture & 44 & $(4.7)$ & 187 & $(27.9)$ & 1814 & $(10.8)$ & 0.4 & $(0.30-0.55)$ & $<0.001$ & 3.2 & $(2.68-3.81)$ & $<0.001$ \\
\hline Ulnar fracture & 33 & $(3.5)$ & 100 & $(14.9)$ & 864 & $(5.1)$ & 0.7 & $(0.47-0.96)$ & 0.032 & 3.2 & $(2.59-4.05)$ & $<0.001$ \\
\hline
\end{tabular}

Table 4. Outcomes of categorical variables in preschool-aged children, school-aged children, and adults.

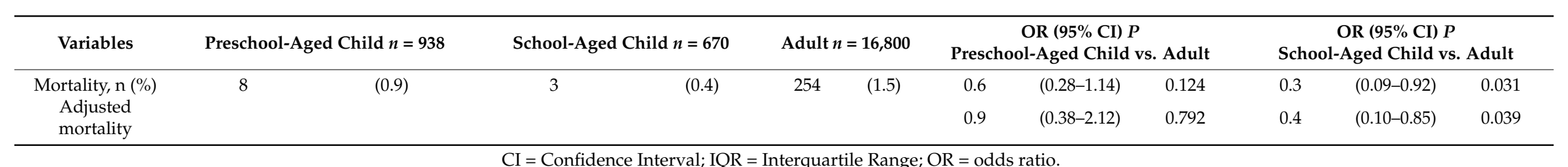




\section{Discussion}

Findings of this study are in accordance with literature that suggests there are certain types of injuries that are common in specific child age group. In a study on 2.4 million pediatric traumatic injury cases in the US from 2000-2011, motorcycle accidents were the most common mechanism of traumatic injuries for all age groups [24]. In children less than 5 years old, burns and abuse were the second and third most common causes of severe traumatic injury. In children aged 5-9 years, falls and animal bites were the second and third most common causes of injuries. Sports were the second most common cause of injury in children aged 10-14 years [24]. This study also found the changing patterns of injuries with age. Burns were the most common injury in preschool-aged children, followed by falls and being struck by/against objects. In school-aged children, falls were the most commonly sustained injury, followed by bicycle accidents, and being struck by/against objects. In addition, injuries as a motorcycle pillion, injuries due to falls, and burn injuries were significantly higher in both preschool-aged and school-aged children than in adult patients. The percentage of preschool-aged children sustaining pedestrian and bite-related injuries is significantly higher than that of adults, but for school-aged children the percentage is not significantly higher than that of adults. Furthermore, bicycle injuries were significantly higher, particularly in school-aged children.

Regarding the associated injuries, this study revealed that preschool-aged and school-aged children had higher odds of humeral fracture than adults. In addition, school-aged children had higher odds of radial fracture and ulnar fracture. The incidence of fractures in children is two times higher than that in adults [25]. From birth until the age of 12 years, all major series have demonstrated a linear increase in the incidence of fractures by age $[25,26]$. The difference in the rates of fractures occurs at a certain age when behaviors change, and the boys tend to develop a more aggressive and risk-taking behavior [25]. In this study, the incidence of fractures in the upper limbs were three-folds higher than that in the lower limbs. This finding is higher than that reported in a previous study conducted in a Taiwanese cohort, which reported that the rates of upper limb injuries were two times higher than those of lower limb injuries [27]. Upper extremity fractures were prevalent among children where shock was absorbed in the upper limb after falling from a climbing equipment or slide [28,29]. Rennie et al. had reported that fracture of the distal radius $(15.3 \%)$ are the most frequent single fractures that occur among children, followed by finger fractures $(14 \%)$, radial and ulnar fractures $(8 \%)$, distal humerus fractures $(7.2 \%)$, and clavicle fractures $(6.8 \%)$ [2].

Previous studies reported that mortality in the pediatric population in all age groups were significantly lower than that in adults [9]. In this study, the odds of mortality in school-aged children was lower than that in adults, but there was no difference in mortality rates between preschool-aged children and adults, either in the presence or absence of controlling for sex, injury mechanisms, and ISS. However, the reason behind the failure to reduction in the odds of mortality among preschool-aged children remains unclear and should raise alarm. In this study, the incidence of other commonly sustained injuries with an associated mortality, including hemothorax or pneumothorax, hepatic injury, and pelvic fracture, was significantly lower in preschool-aged child than in adults. In particular, the incidence of TBI, including neurologic deficit, subdural hemorrhage, subarachnoid hemorrhage, intracerebral hematoma and cerebral contusion in preschool-aged children was even lower than that in adults.

Although majority of childhood head injuries are minor, approximately $5 \%$ of these injuries can cause mortality or lead to intracranial complications [30]. In a study conducted in 216 participating hospitals, intracranial injury or skull fracture occurred in one out of ten children, with the overall mortality being $0.4 \%$, and these injuries were predominant among victims of motor vehicle accidents or abusive head trauma [31]. Unlike those studies conducted in Western countries, the occurrence of motor vehicle accidents were much lower in Taiwan. In this study, only $0.7 \%$ and $1.2 \%$ of preschool-aged and school-age child respectively had sustained injuries as a passenger in the motor vehicle accidents. In Taiwan, nearly $60 \%$ of all trauma injuries and driving fatalities involving motorcycle accidents [32]. It had been reported that, in Taiwan, the mortality rate of motorcyclists 
using helmets was significantly lower than those not using helmets $(1.1 \% \mathrm{vs.} .4 \%$, respectively; OR, $0.2 ; 95 \% \mathrm{CI}, 0.17-0.37 ; p<0.001$ ) [33]. However, in this study, the rates of injuries as a motorcycle pillion in both preschool-aged and school-aged children were higher than that in adult patients. Besides, helmet use was significantly associated with lower odds of head injury in school-aged children (OR 0.1; 95\% CI 0.02-0.37; $p<0.001$ ) but not in preschool-aged children (OR $0.7 ; 95 \%$ CI $0.21-2.31 ; p=0.768$ ). Whether the failure to protect a fatal head injury in preschool-aged child is attributable to a mismatch between the sizes of helmets and their heads requires further investigation to confirm. However, the implementation of more effective methods to reduce motorcycle accidents and the strict use of a protective helmets in motorcycle pillions in accordance with the traffic laws may be effective to reduce the occurrence of head injury and its associated mortality.

This study also revealed that preschool-aged children are at heightened risk for pedestrian injuries than adults. Interventions such as modification of the road environment [34], implementation of a higher number of student crossings, a wider road width, the presence of crosswalks, student-friendly facilities at the intersection, and four-way intersections [35] may help to reduce the pedestrian crashes. For example, the implementation of the Safe Routes to School (SRTS) program in New York City has contributed to a substantial $44 \%$ reduction in pedestrian injuries among school-aged children [36].

This study had several limitations. First, although the cutoff value for preschool-aged vs. school-aged children was chosen based on the situation in Taiwan, the profile of childhood injury may change greatly over the first three or four years of life. Therefore, grouping the first seven years together for analysis may have lead to a selection bias. Second, an inherent selection bias already existed because of the retrospective study design, particularly when considering the circumstances of injuries, the impact force of each injury, and the pre-existing comorbidities that were left unrecorded (although the incidence of these comorbidities is expected to be much lower in children than that in adults). Third, this study focused on hospitalized pediatric patients only; however, many minor injuries sustained at certain sites are manageable and do not require hospital admissions, which may lead to underestimation on the incidence of associated illness, particularly the fractures, burns, or dog bite injuries, and may result in a selection bias. Fourth, these data systems do not capture important non-fatal outcomes, such as functional status or quality of life outcomes. Considering the difference of the remaining lifespan in the pediatric and adult victims, it is important to evaluate the burden of trauma in the lives of pediatric patients. Fifth, the number of preschool-aged and school-aged children with fatal injuries was lower than that of adults, which may result in a potential source of methodological bias in the assessment. Finally, the study was conducted only in patients admitted in a level I trauma center; whether children received suboptimal prehospital care compared to the adults at a level I trauma center and not at a pediatric trauma center would raise further debate; so the results of this study remained inconclusive [37-39].

\section{Conclusions}

This study suggests that preschool-aged and school-aged children dominate specific types of injuries from different injury mechanisms. The school-aged children had lower odds of mortality than adults. However, such reduction in mortality was not seen in the preschool-aged children compared to adults, either in the presence or absence of controlling for sex, injury mechanisms, and ISS. These results highlighted the importance of injury prevention particularly in the preschool-aged children in Southern Taiwan.

Supplementary Materials: The following are available online at http:/ /www.mdpi.com/1660-4601/15/5/858/s1. Table S1: The association of head injury and helmet use in the motorcycle pillion of preschool-aged and school-aged children; Table S2: Associated injuries in the six main body regions; Table S3: Comparison of associated injuries in the six main body regions.

Author Contributions: S.-H.P. wrote the manuscript, C.-Y.H. edited the tables, S.-Y.H. validated the collected data and performed the statistical analyses, L.-H.Y. helped design the study, and C.-H.H. contributed to the study design, interpreted the data, and was responsible for the integrity of the data. All authors read and approved the final manuscript. 
Funding: This research was supported by a grant from Chang Gung Memorial Hospital (CMRPG8G1301).

Acknowledgments: We appreciate the Biostatistics Center of Kaohsiung Chang Gung Memorial Hospital for the statistical work.

Conflicts of Interest: The authors declare no conflicts of interest.

\section{References}

1. Danseco, E.R.; Miller, T.R.; Spicer, R.S. Incidence and costs of 1987-1994 childhood injuries: Demographic breakdowns. Pediatrics 2000, 105, E27. [CrossRef] [PubMed]

2. Rennie, L.; Court-Brown, C.M.; Mok, J.Y.; Beattie, T.F. The epidemiology of fractures in children. Injury 2007, 38, 913-922. [CrossRef] [PubMed]

3. Myers, S.R.; Branas, C.C.; French, B.; Nance, M.L.; Carr, B.G. A National Analysis of Pediatric Trauma Care Utilization and Outcomes in the United States. Pediatr. Emerg. Care 2016. [CrossRef] [PubMed]

4. Centers for Disease Control and Prevention. National Action Plan for Child Injury Prevention: An Agenda to Prevent Injuries and Promote the Safety of Children and Adolescents in the United States; National Center for Injury Prevention and Control, Centers for Disease Control and Prevention: Atlanta, GA, USA, 2012.

5. Abubakar, I.I.; Tillmann, T.; Banerjee, A. Global, regional, and national age-sex specific all-cause and cause-specific mortality for 240 causes of death, 1990-2013: A systematic analysis for the Global Burden of Disease Study 2013. Lancet 2015, 385, 117-171.

6. Vallipakorn, S.A.; Plitapolkarnpim, A.; Suriyawongpaisal, P.; Techakamolsuk, P.; Smith, G.A.; Thakkinstian, A. Risk prediction score for death of traumatised and injured children. BMC Pediatr. 2014, 14, 60. [CrossRef] [PubMed]

7. Borse, N.N.; Rudd, R.A.; Dellinger, A.M.; Sleet, D.A. Years of potential life lost from unintentional child and adolescent injuries-United States, 2000-2009. J. Saf. Res. 2013, 45, 127-131. [CrossRef] [PubMed]

8. Borse, N.; Sleet, D.A. CDC Childhood Injury Report: Patterns of Unintentional Injuries among 0-19-Year-Old in the United States, 2000-2006. Available online: https://www.cdc.gov/safechild/images/CDCchildhoodinjury.pdf (accessed on 1 January 2018).

9. Centers for Disease Control and Prevention. Web-Based Injury Statistics Query and Reporting System (WISQARS). National Center for Injury Prevention and Control, 2015. Available online: http:/ / www.cdc. gov /injury/wisqars/index.html (accessed on 1 January 2018).

10. Ochoa, C.; Chokshi, N.; Upperman, J.S.; Jurkovich, G.J.; Ford, H.R. Prior studies comparing outcomes from trauma care at children's hospitals versus adult hospitals. J. Trauma 2007, 63 (Suppl. 6), S87-S91. [CrossRef] [PubMed]

11. Mytton, J.; Towner, E.; Brussoni, M.; Gray, S. Unintentional injuries in school-aged children and adolescents: Lessons from a systematic review of cohort studies. Inj. Prev. 2009, 15, 111-124. [CrossRef] [PubMed]

12. Swaid, F.; Peleg, K.; Alfici, R.; Olsha, O.; Givon, A.; Kessel, B. A comparison study of pelvic fractures and associated abdominal injuries between pediatric and adult blunt trauma patients. J. Pediatr. Surg. 2017, 52, 386-389. [CrossRef] [PubMed]

13. James, H.E. Pediatric head injury: What is unique and different. In Current Progress in the Understanding of Secondary Brain Damage from Trauma and Ischemia; Springer: Vienna, Austria, 1999; Volume 73, pp. 85-88.

14. Bonanno, G.A.; Mancini, A.D. The human capacity to thrive in the face of potential trauma. Pediatrics 2008, 121, 369-375. [CrossRef] [PubMed]

15. Upperman, J.S.; Burd, R.; Cox, C.; Ehrlich, P.; Mooney, D.; Groner, J.I. Pediatric applied trauma research network: A call to action. J. Trauma 2010, 69, 1304-1307. [CrossRef] [PubMed]

16. Wu, A.L.; See, L.C.; Hsia, S.H.; Tu, H.T.; Wang, N.K.; Huang, J.L.; Hwang, Y.S.; Lai, C.C.; Wu, W.C. Pediatric abusive head trauma in Taiwan: Clinical characteristics and risk factors associated with mortality. Graefes Arch. Clin. Exp. Ophthalmol. 2018, 256, 1-7. [CrossRef] [PubMed]

17. Lee, E.P.; Hsia, S.H.; Huang, J.L.; Lin, J.J.; Chan, O.W.; Lin, C.Y.; Lin, K.L.; Chang, Y.C.; Chou, I.J.; Lo, F.S.; et al. Epidemiology and clinical analysis of critical patients with child maltreatment admitted to the intensive care units. Medicine 2017, 96, e7107. [CrossRef] [PubMed]

18. Tung, K.Y.; Chen, M.L.; Wang, H.J.; Chen, G.S.; Peck, M.; Yang, J.; Liu, C.C. A seven-year epidemiology study of 12,381 admitted burn patients in Taiwan-Using the Internet registration system of the Childhood Burn Foundation. Burns 2005, 31 (Suppl. 1), S12-S17. [CrossRef] [PubMed] 
19. Chen, C.L.; Wong, M.K.; See, L.C.; Chong, C.K. Head injuries in children and adolescents: Causes and natures. Changgeng Yi Xue Za Zhi 1995, 18, 353-360. [PubMed]

20. Costello, E.J.; Erkanli, A.; Fairbank, J.A.; Angold, A. The prevalence of potentially traumatic events in childhood and adolescence. J. Trauma. Stress 2002, 15, 99-112. [CrossRef] [PubMed]

21. Hsieh, C.H.; Hsu, S.Y.; Hsieh, H.Y.; Chen, Y.C. Differences between the sexes in motorcycle-related injuries and fatalities at a Taiwanese level I trauma center. Biomed. J. 2017, 40, 113-120. [CrossRef] [PubMed]

22. Hsieh, C.H.; Liu, H.T.; Hsu, S.Y.; Hsieh, H.Y.; Chen, Y.C. Motorcycle-related hospitalizations of the elderly. Biomed. J. 2017, 40, 121-128. [CrossRef] [PubMed]

23. Baker, S.P.; O'Neill, B.; Haddon, W., Jr.; Long, W.B. The injury severity score: A method for describing patients with multiple injuries and evaluating emergency care. J. Trauma 1974, 14, 187-196. [CrossRef] [PubMed]

24. Oliver, J.; Avraham, J.; Frangos, S.; Tomita, S.; DiMaggio, C. The epidemiology of inpatient pediatric trauma in United States hospitals 2000 to 2011. J. Pediatr. Surg. 2017, 53, 758-764. [CrossRef] [PubMed]

25. Schalamon, J.; Dampf, S.; Singer, G.; Ainoedhofer, H.; Petnehazy, T.; Hoellwarth, M.E.; Saxena, A.K. Evaluation of fractures in children and adolescents in a Level I Trauma Center in Austria. J. Trauma 2011, 71, E19-E25. [CrossRef] [PubMed]

26. Landin, L.A. Fracture patterns in children. Analysis of 8682 fractures with special reference to incidence, etiology and secular changes in a Swedish urban population 1950-1979. Acta Orthop. Scand. Suppl. 1983, 202, 1-109. [PubMed]

27. Yang, C.Y.; Yeh, Y.C.; Cheng, M.F.; Lin, M.C. The incidence of school-related injuries among adolescents in Kaohsiung, Taiwan. Am. J. Prev. Med. 1998, 15, 172-177. [CrossRef]

28. Hogan, C.M.; Weaver, N.L.; Cioni, C.; Fry, J.; Hamilton, A.; Thompson, S. Parental Perceptions, Risks, and Incidence of Pediatric Unintentional Injuries. J. Emerg. Nurs. 2017. [CrossRef] [PubMed]

29. Bae, S.; Lee, J.S. Playground Equipment Related Injuries in Preschool-Aged Children: Emergency Department-based Injury In-depth Surveillance. J. Korean Med. Sci. 2017, 32, 534-541. [CrossRef] [PubMed]

30. Stewart, T.C.; Gilliland, J.; Fraser, D.D. An epidemiologic profile of pediatric concussions: Identifying urban and rural differences. J. Trauma Acute Care Surg. 2014, 76, 736-742. [CrossRef] [PubMed]

31. Trefan, L.; Houston, R.; Pearson, G.; Edwards, R.; Hyde, P.; Maconochie, I.; Parslow, R.C.; Kemp, A. Epidemiology of children with head injury: A national overview. Arch. Dis. Child. 2016, 101, 527-532. [CrossRef] [PubMed]

32. Liang, C.C.; Liu, H.T.; Rau, C.S.; Hsu, S.Y.; Hsieh, H.Y.; Hsieh, C.H. Motorcycle-related hospitalization of adolescents in a Level I trauma center in southern Taiwan: A cross-sectional study. BMC Pediatr. 2015, 15, 105. [CrossRef] [PubMed]

33. Kuo, S.C.H.; Kuo, P.J.; Rau, C.S.; Chen, Y.C.; Hsieh, H.Y.; Hsieh, C.H. The protective effect of helmet use in motorcycle and bicycle accidents: A propensity score-matched study based on a trauma registry system. BMC Public Health 2017, 17, 639. [CrossRef] [PubMed]

34. Retting, R.A.; Ferguson, S.A.; McCartt, A.T. A review of evidence-based traffic engineering measures designed to reduce pedestrian-motor vehicle crashes. Am. J. Public Health 2003, 93, 1456-1463. [CrossRef] [PubMed]

35. Lee, G.; Park, Y.; Kim, J.; Cho, G.H. Association between intersection characteristics and perceived crash risk among school-aged children. Accid. Anal. Prev. 2016, 97, 111-121. [CrossRef] [PubMed]

36. Dimaggio, C.; Li, G. Effectiveness of a safe routes to school program in preventing school-aged pedestrian injury. Pediatrics 2013, 131, 290-296. [CrossRef] [PubMed]

37. Bankole, S.; Asuncion, A.; Ross, S.; Aghai, Z.; Nollah, L.; Echols, H.; Da-Silva, S. First responder performance in pediatric trauma: A comparison with an adult cohort. Pediatr. Crit. Care Med. 2011, 12, e166-e170. [CrossRef] [PubMed] 
38. Hansen, M.; Meckler, G.; Dickinson, C.; Dickenson, K.; Jui, J.; Lambert, W.; Guise, J.M. Children's safety initiative: A national assessment of pediatric educational needs among emergency medical services providers. Prehosp. Emerg. Care 2015, 19, 287-291. [CrossRef] [PubMed]

39. Seid, T.; Ramaiah, R.; Grabinsky, A. Pre-hospital care of pediatric patients with trauma. Int. J. Crit. Illn. Inj. Sci. 2012, 2, 114-120. [PubMed] 